Pacific Journal of Mathematics

ON HOMOMORPHISMS OF MATRIX ALGEBRAS OF 


\title{
ON HOMOMORPHISMS OF MATRIX ALGEBRAS OF CONTINUOUS FUNCTIONS
}

\section{MARIUS DÁDǍRlat}

\begin{abstract}
If $X$ is a topological space we denote by $C(X) \otimes M_{n}$ the algebra of continuous functions from $X$ to the algebra $M_{n}$ of $n \times n$ complex matrices. A complete characterization of those topological spaces $Y$ is given (in terms of vector bundles on $Y$ ) such that each unital algebrahomomorphism $\Phi: C(X) \otimes M_{n} \rightarrow C(Y) \otimes M_{k n}$ is of the form $\alpha$ 。 $\left(\Phi^{\prime} \otimes \mathrm{id}_{n}\right)$ for some homomorphism $\Phi^{\prime}: C(X) \rightarrow C(Y) \otimes M_{k}$ and some suitable inner (or $C(Y)$-linear) automorphism $\alpha$ of the algebra $C(Y) \otimes M_{k n}$. In particular this decomposition is assured provided that $Y$ is a finite $\mathbf{C W}$-complex of dimension $\leq 2 k$ and $K^{0}(Y)$ does not have $n$-torsion.
\end{abstract}

Our interest in such homomorphisms arose in connection with a question of E. G. Effros [1] concerning the structure of inductive limits of $C^{*}$-algebras of the form $C(X) \otimes M_{n}$. In this context certain classes of homomorphisms related to a covering $X \rightarrow Y$ have been considered by C. Pasnicu [5]. When restricted to the case of automorphisms our results give nothing new (see [4], [6] and [7]).

1. Preliminaries. Let $\mathrm{GL}_{n}(C)$ be the general linear group (nonsingular $n \times n$ matrices over the complex field) and denote by $1_{n}$ its unit. Let $\operatorname{Vect}_{m}(Y)$ denote the set of isomorphism classes of complex vector bundles of rank $m$ on the topological space $Y$. In $\operatorname{Vect}_{m}(Y)$ we have one naturally distinguished element-the class of the trivial bundle of rank $m$. Let $T_{n} \operatorname{Vect}_{m}(Y)$ be the subset of $\operatorname{Vect}_{m}(Y)$ given by all vector bundles $E$ such that the direct sum $E \oplus E \oplus \cdots \oplus E$ (n-times) is isomorphic to the trivial bundle of rank $\mathrm{nm}$.

If $A, B$ are unital complex algebras we denote by $\operatorname{Hom}(A, B)$ the set of all unital algebra-homomorphisms from $A$ to $B$. Two homomorphisms $\Phi_{1}, \Phi_{2} \in \operatorname{Hom}(A, B)$ are said to be inner equivalent if $\Phi_{2}=u \Phi_{1} u^{-1}$ for some invertible element $u \in B$. Let $\operatorname{Hom}(A, B) / \sim$ be the set of classes of inner equivalent homomorphisms from $A$ to B.

We need some elementary sheaf cohomology. Let $G$ be a Lie group and let $H$ be a closed subgroup of $G$. For each topological space $Y$ the fibration $H \rightarrow G \rightarrow G / H$ induces the following exact sequence of 
pointed cohomology sets:

$$
H^{0}(Y, H) \rightarrow H^{0}(Y, G) \rightarrow H^{0}(Y, G / H) \stackrel{\delta}{\rightarrow} H^{1}(Y, H) \rightarrow H^{1}(Y, G) .
$$

We have $H^{0}(Y, H)=C(Y, H)$ (continuous maps from $Y$ to $H$ ) and $H^{0}(Y, G)=C(Y, G)$. These sets are pointed by the constant map $f=$ $1_{G}$ given by the unity of $G$. Similarly $H^{0}(Y, G / H)=C(Y, G / H)$ is pointed by the constant map $f=\{H\}$. The cohomology sets $H^{1}(Y, H)$ and $H^{1}(Y, G)$ are pointed by the trivial cocycles $\left(Y, 1_{H}\right)$ and $\left(Y, 1_{G}\right)$ respectively [2]. Given $f \in C(Y, G / H)$ the cocycle $\delta(f)$ represents the obstruction for lifting $f$ to a function in $C(Y, G)$. By the exactness of the above sequence $f$ has a continuous lifting if and only if $\delta(f)=$ $\left(Y, 1_{H}\right)$. The action of $G$ on $G / H$ induces an action of $C(Y, G)$ on $C(Y, G / H)$. If $f_{1}, f_{2} \in C(Y, G / H)$ then $\delta\left(f_{1}\right)=\delta\left(f_{2}\right)$ if and only if $f_{2}=g f_{1}$ for some $g \in C(Y, G)$.

\section{Results.}

Proposition 1. Let $Y$ be a topological space. Then there is a bijection $\operatorname{Hom}\left(M_{n}, C(Y) \otimes M_{k n}\right) / \sim \rightarrow T_{n} \operatorname{Vect}_{k}(Y)$.

Proof. We describe the exact sequence induced by the following fibration:

$$
\mathrm{GL}_{k}(C) \stackrel{\vartheta}{\rightarrow} \mathrm{GL}_{k n}(C) \stackrel{j}{\rightarrow} \mathrm{GL}_{k n}(C) / \mathrm{GL}_{k}(C)
$$

where the imbedding $\gamma$ is given by

$$
\gamma(u)=u \otimes 1_{n}, \quad M_{k n}=M_{k} \otimes M_{n} .
$$

There is a commutative diagram of pointed sets:

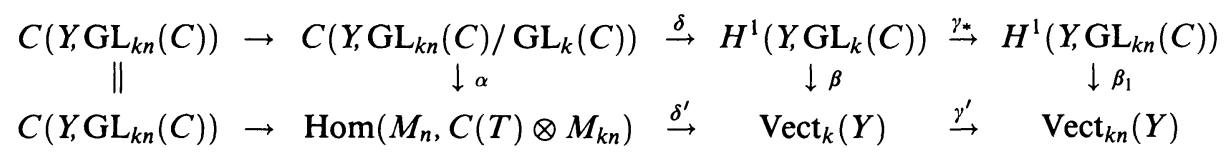

The vertical arrows are bijections. To describe $\alpha$ recall that

$$
\operatorname{Hom}\left(M_{n}, M_{k n}\right) \simeq \mathrm{GL}_{k n}(C) / \mathrm{GL}_{k}(C)
$$

as topological spaces, the homeomorphism being induced by the map $\eta: \mathrm{GL}_{k n}(C) \rightarrow \operatorname{Hom}\left(M_{n}, M_{k n}\right)$ given by $\eta(v)(a)=v\left(1_{k} \otimes a\right) v^{-1}$, $a \in M_{n}$. Let $\eta_{1}$ be the map

$$
C\left(Y, \mathrm{GL}_{k n}(C) / \mathrm{GL}_{k}(C)\right) \rightarrow C\left(Y, \operatorname{Hom}\left(M_{n}, M_{k n}\right)\right)
$$

induced by $\eta$. By definition we set $\alpha=\alpha_{1} \eta_{1}$ where

$$
\alpha_{1}: C\left(Y, \operatorname{Hom}\left(M_{n}, M_{k n}\right)\right) \rightarrow \operatorname{Hom}\left(M_{n}, C(Y) \otimes M_{k n}\right)
$$


is given by $\alpha_{1}(\Psi)(a)(y)=\Psi(y)(a), a \in M_{n}, y \in Y$. If in

$$
\operatorname{Hom}\left(M_{n}, C(Y) \otimes M_{k n}\right)
$$

we distinguish the homomorphism $a \mapsto a \otimes 1_{k}, \alpha$ will be an isomorphism of pointed sets. The maps $\beta$ and $\beta_{1}$ are the natural ones. Namely if $\left(U_{i}, g_{i j}\right)$ is a $\mathrm{GL}_{k}$-cocycle, then $\beta\left(U_{i}, g_{i j}\right)$ is the isomorphism class of the vector bundle obtained by clutching the trivial bundles $U_{i} \times C^{k}$ with the transition functions $\left(g_{i j}\right)$. The map $\beta_{1}$ is defined in a similar way. The other maps are defined to make the diagram commutative. If $v \in C\left(Y, \mathrm{GL}_{k n}(C)\right)$ then $j^{\prime}(v): M_{n} \rightarrow C(Y) \otimes M_{k n}$ is defined by

$$
j^{\prime}(v)(a)(y)=v(y)\left(1_{k} \otimes a\right) v(y)^{-1}, \quad a \in M_{n}, \quad y \in Y .
$$

The map $\gamma^{\prime}$ takes the vector bundle $E$ to the direct sum $E \oplus E \oplus$ $\cdots \oplus E$ ( $n$-times). After the above identifications, it follows that two homomorphisms $\Phi_{1}, \Phi_{2} \in \operatorname{Hom}\left(M_{n}, C(Y) \otimes M_{k n}\right)$ are inner equivalent if and only if $\delta^{\prime}\left(\Phi_{1}\right)=\delta^{\prime}\left(\Phi_{2}\right)$. The isomorphism class of the vector bundle $\delta^{\prime}\left(\Phi_{1}\right)$ represents the obstruction for lifting $\Phi_{1}$ to an invertible element in $C(Y) \otimes M_{k n}$. Also, by the exactness of the second row in the above diagram, the image of $\delta^{\prime}$ is equal to $T_{n} \operatorname{Vect}_{k}(Y)$.

THEOREM 2. Let $X, Y$ be topological spaces. Then the following assertions are equivalent:

(i) The set $T_{n} \operatorname{Vect}_{k}(Y)$ reduces to the trivial bundle of rank $k$.

(ii) Each homomorphism $\Phi \in \operatorname{Hom}\left(C(X) \otimes M_{n}, C(Y) \otimes M_{k n}\right)$ is inner equivalent to a homomorphism of the form $\Phi^{\prime} \otimes \mathrm{id}_{n}$ for some $\Phi^{\prime} \in \operatorname{Hom}\left(C(X), C(Y) \otimes M_{k}\right)$.

Proof. The implication (i) $\Rightarrow$ (ii) follows easily from Proposition 1. Indeed, if we choose a point $x$ in $X$ and a homomorphism $\Phi_{1}$ in $\operatorname{Hom}\left(M_{n}, C(Y) \otimes M_{k n}\right)$ which is not inner equivalent to the homomorphism $a \mapsto 1_{k} \otimes a$ then the homomorphism $C(X) \otimes M_{n} \ni F \mapsto$ $\Phi_{1}(F(x)) \in C(Y) \otimes M_{k n}$ failed to satisfy (ii).

To prove the other implication we assume, as a preliminary step, that $\Phi$ acts on matrices as an amplification:

$$
\Phi\left(1_{C(X)} \otimes a\right)=1_{C(Y)} \otimes 1_{k} \otimes a, \quad a \in M_{n} .
$$

Under this assumption we get

$$
\begin{aligned}
\Phi(f \otimes a) & =\Phi\left(f \otimes 1_{n}\right) \Phi(1 \otimes a)=\Phi(1 \otimes a) \Phi\left(f \otimes 1_{n}\right) \\
& =1 \otimes 1_{k} \otimes a \cdot \Phi\left(f \otimes 1_{n}\right), \quad a \in M_{n}, f \in C(X) .
\end{aligned}
$$


The previous computation shows us that the algebra $\Phi\left(C(X) \otimes 1_{n}\right)$ lies in the relative commutant of $1_{C(Y)} \otimes 1_{k} \otimes M_{n}$ in $C(Y) \otimes M_{k} \otimes M_{n}$ which is equal to $C(Y) \otimes M_{k} \otimes 1_{n}$. It follows that there is a unique homomorphism $\Phi^{\prime} \in \operatorname{Hom}\left(C(X), C(Y) \otimes M_{k}\right)$ such that $\Phi\left(f \otimes 1_{n}\right)=$ $\Phi^{\prime}(f) \otimes 1_{n}$. Using again our assumption on $\Phi$ we get $\Phi=\Phi^{\prime} \otimes \mathrm{id}_{n}$.

Consider now an arbitrary homomorphism $\Phi$ and let $\Phi_{1}$ denote its restriction to $M_{n}$. Using (i) it follows by Proposition 1 that there is some invertible element $u \in C(Y) \otimes M_{k n}$ such that

$$
\Phi_{1}(a)=\Phi(1 \otimes a)=u\left(1 \otimes 1_{k} \otimes a\right) u^{-1}, \quad a \in M_{n} .
$$

Hence the homomorphism $u^{-1} \Phi u$ acts on matrices as an amplification.

REMARK 3. The assertion (i) in the above theorem holds provided that $Y$ is homotopy equivalent to a finite $\mathrm{CW}$-complex of dimension $\leq 2 k$ and the $K$-theory group $K^{0}(Y)$ does not have $n$-torsion. This follows from the stability properties of vector bundles (see [3, Ch. 8, Th. 1.5]).

Note that $T_{n} \operatorname{Vect}_{1}(Y)$ is a subgroup of the group $\left(\operatorname{Vect}_{1}(Y), \otimes\right)$. We have a natural action of $T_{n} \operatorname{Vect}_{1}(Y)$ on $T_{n} \operatorname{Vect}_{k}(Y)$ given by $(L, E) \mapsto$ $L \otimes E$. By similar methods one can prove the following

Theorem 4. Let $X, Y$ be topological spaces. Then the following assertions are equivalent:

(i) $T_{n} \operatorname{Vect}_{1}(Y)$ acts transitively on $T_{n} \operatorname{Vect}_{k}(Y)$.

(ii) For any homomorphism $\Phi \in \operatorname{Hom}\left(C(X) \otimes M_{n}, C(Y) \otimes M_{k n}\right)$ there is an automorphism $\alpha$ of $C(Y) \otimes M_{k n}$ which is $C(Y)$-linear such that $\alpha \circ \Phi=\Phi^{\prime} \otimes \mathrm{id}_{n}$ for some homomorphism $\Phi^{\prime} \in \operatorname{Hom}(C(X), C(Y) \otimes$ $\left.M_{k}\right)$.

\section{REFERENCES}

[1] E. G. Effros, On the structure of $C^{*}$-algebras: Some old and some new problems, in Operator Algebras and Applications. Proc. Symp. Pure Math., Amer. Math. Soc., Providence, RI, 1982.

[2] F. Hirzebruch, Topological Methods in Algebraic Geometry, Springer-Verlag, New York, 1965.

[3] D. Husemoller, Fibre Bundles, McGraw-Hill Book Company, 1966.

[4] R. V. Kadison and J. R. Ringrose, Derivations and automorphisms of operator algebras, Commun. Math. Phys., 4 (1967), 32-63.

[5] C. Pasnicu, On certain inductive limit $C^{*}$-algebras, Indiana Univ. Math. J., 35 (1986), 269-288.

[6] J. Phillips and I. Raeburn, Automorphisms of $C^{*}$-algebras and second Cech cohomology, Indiana Univ. Math. J., 29 (1980), 799-822. 
[7] K. Thomsen, Automorphisms of homogeneous $C^{*}$-algebras, Bull. Austral. Math. Soc., 33 (1986), 145-154.

Received December 15, 1986.

The National Institute for Scientific and Technical Creation BDUl PaCII 220

79622 BUCHAREST, ROMANIA 



\title{
PACIFIC JOURNAL OF MATHEMATICS EDITORS
}

\author{
V. S. VARADARAJAN \\ (Managing Editor) \\ University of California \\ Los Angeles, CA 90024 \\ HERBERT Clemens \\ University of Utah \\ Salt Lake City, UT 84112 \\ R. FINN \\ Stanford University \\ Stanford, CA 94305
}

\author{
HERMANN FLASCHKA \\ University of Arizona \\ Tucson, AZ 85721
}

Ramesh A. Gangolli University of Washington Seattle, WA 98195

VAUGHAN F. R. JONES University of California Berkeley, CA 94720
ROBION KIRBY

University of California

Berkeley, CA 94720

C. C. MOORE

University of California

Berkeley, CA 94720

HAROLD STARK

University of California, San Diego La Jolla, CA 92093

\section{ASSOCIATE EDITORS}

\author{
R. ARENS \\ E. F. BECKENBACH \\ B. H. NEUMANN \\ F. WOLF \\ K. YOSHIDA \\ (1906-1982)

\section{SUPPORTING INSTITUTIONS}

\section{UNIVERSITY OF ARIZONA} \\ UNIVERSITY OF BRITISH COLUMBIA \\ CALIFORNIA INSTITUTE OF TECHNOLOGY \\ UNIVERSITY OF CALIFORNIA \\ MONTANA STATE UNIVERSITY \\ UNIVERSITY OF NEVADA, RENO \\ NEW MEXICO STATE UNIVERSITY \\ OREGON STATE UNIVERSITY \\ UNIVERSITY OF OREGON \\ UNIVERSITY OF SOUTHERN CALIFORNIA \\ STANFORD UNIVERSITY \\ UNIVERSITY OF HAWAII \\ UNIVERSITY OF TOKYO \\ UNIVERSITY OF UTAH \\ WASHINGTON STATE UNIVERSITY \\ UNIVERSITY OF WASHINGTON
}

The Supporting Institutions listed above contribute to the cost of publication of this Journal, but they are not owners or publishers and have no responsibility for its content or policies.

Mathematical papers intended for publication in the Pacific Journal of Mathematics should be in typed form or offset-reproduced (not dittoed), double spaced with large margins. Please do not use built up fractions in the text of the manuscript. However, you may use them in the displayed equations. Underline Greek letters in red, German in green, and script in blue. The first paragraph must be capable of being used separately as a synopsis of the entire paper. In particular it should contain no bibliographic references. Please propose a heading for the odd numbered pages of less than 35 characters. Manuscripts, in triplicate, may be sent to any one of the editors. Please classify according to the scheme of Math. Reviews, Index to Vol. 39. Supply name and address of author to whom proofs should be sent. All other communications should be addressed to the managing editor, or Elaine Barth, University of California, Los Angeles, California 90024

There are page-charges associated with articles appearing in the Pacific Journal of Mathematics. These charges are expected to be paid by the author's University, Government Agency or Company. If the author or authors do not have access to such Institutional support these charges are waived. Single authors will receive 50 free reprints; joint authors will receive a total of 100 free reprints. Additional copies may be obtained at cost in multiples of 50 .

The Pacific Journal of Mathematics is issued monthly as of January 1966. Regular subscription rate: $\$ 190.00$ a year (5 Vols., 10 issues). Special rate: $\$ 95.00$ a year to individual members of supporting institutions.

Subscriptions, orders for numbers issued in the last three calendar years, and changes of address should be sent to Pacific Journal of Mathematics, P.O. Box 969, Carmel Valley, CA 93924, U.S.A. Old back numbers obtainable from Kraus Periodicals Co., Route 100, Millwood, NY 10546.

The Pacific Journal of Mathematics at P.O. Box 969, Carmel Valley, CA 93924 (ISSN 0030-8730) publishes 5 volumes per year. Application to mail at Second-class postage rates is pending at Carmel Valley, California, and additional mailing offices. Postmaster: send address changes to Pacific Journal of Mathematics, P.O. Box 969, Carmel Valley, CA 93924.

PUBLISHED BY PACIFIC JOURNAL OF MATHEMATICS, A NON-PROFIT CORPORATION Copyright (C) 1988 by Pacific Journal of Mathematics 


\section{Pacific Journal of Mathematics}

\section{Vol. 132, No. $2 \quad$ February, 1988}

Jeffery Marc Bergen and Luisa Carini, A note on derivations with power central values on a Lie ideal ..............................209

Alfonso Castro and Sumalee Unsurangsie, A semilinear wave equation

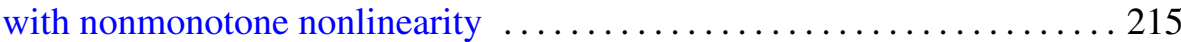

Marius Dadarlat, On homomorphisms of matrix algebras of continuous

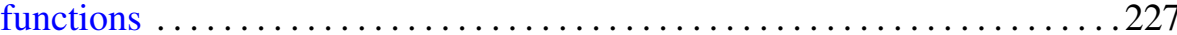

A. Didierjean, Quelques classes de cobordisme non orienté refusant de se

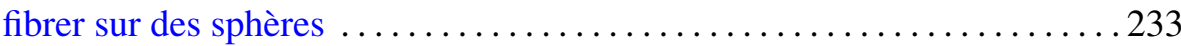

Edward George Effros and Zhong-Jin Ruan, On matricially normed spaces

Sherif El-Helaly and Taqdir Husain, Orthogonal bases are Schauder bases

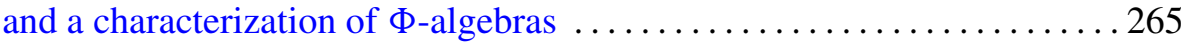

Edward Richard Fadell and Peter N-S Wong, On deforming $G$-maps to be

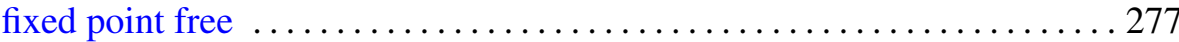

Jean-Jacques Gervais, Stability of unfoldings in the context of equivariant

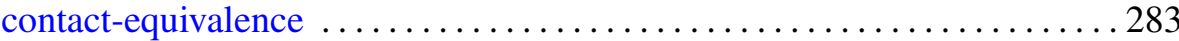

Douglas Martin Grenier, Fundamental domains for the general linear group

Ronald Scott Irving and Brad Shelton, Loewy series and simple projective

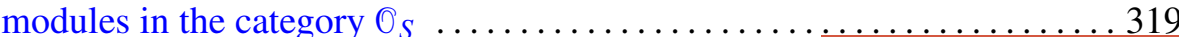

Russell Allan Johnson, On the Sato-Segal-Wilson solutions of the K-dV equation

Thomas Alan Keagy and William F. Ford, Acceleration by subsequence transformations

Min Ho Lee, Mixed cusp forms and holomorphic forms on elliptic varieties

Charles Livingston, Indecomposable surfaces in 4-space 